\title{
New technique of combined hot air and microwave drying to produce a new fiber ingredient from industrial by-products
}

Talens, C. ${ }^{\text {a*; Castro-Giraldez, M. }{ }^{\text {; }} \text {; Fito, P.J. }}$ b

a AZTI—Food Research, Parque Tecnológico de Bizkaia, Astondo Bidea, Edificio 609, 48160 Derio, Bizkaia, Spain

b Instituto Universitario de Ingeniería de Alimentos para el Desarrollo, Universidad Politécnica de Valencia, Camino de Vera s/n, 46022 Valencia, Spain

*E-mail of the corresponding author: ctalens@azti.es

\begin{abstract}
The search for solutions to transform the by-products generated by the agrifood sector in high value-added ingredients is a priority. The aim of this research was to develop a microwave coupled with hot air drying technique allowing maximizing profits by reducing time and operational costs and to produce a dietary fiber ingredient with interesting technological properties for the development of healthy foods. The shrinkage-swelling phenomena occurred during drying changed the rehydration properties of the fibre ingredient obtained. An increase in particle size improved the fibre's swelling capacity when hydrated, allowing $50 \%$ fat substitution in potato purees.
\end{abstract}

Keywords: hot air-microwave drying; orange peel; thermodynamics; $G A B$ model; dietary fibre 
New technique of combined hot air and microwave drying to produce a new fiber ingredient from industrial byproducts

\section{Introduction}

Sustainability is nowadays an investment for the future of any economic activity. The current situation of crisis has had an adverse impact in most industries, including the agrifood sector. However, this industry has been relatively the least affected when compared with other industrial sectors. This is mainly attributed to the fact that food products continue to be basic for consumers despite the economic downturn. Therefore, the agri-food sector is a key element in the European economy and can play a crucial role in the achievement of the objectives set in the EU's strategy for 2020: ensuring a sustainable framework of growth of a more competitive economy. The European agri-food industry has focused on energy efficiency and on reducing greenhouse gases emissions, along with better management of their resources as a way to improve its industrial competitiveness. In this sense, the search for solutions to transform the by-products generated in high valueadded ingredients, is a priority. In this context, the juice industry, as fundamental sub-sector within the food sector, and large waste generator, must exploit the opportunity to transform their by-products into useful and profitable products for society. This transformation presents some difficulties which impede the profitability of the process. These difficulties are associated with the by-product, such as its compositional variability and its seasonality, and current techniques of transformation as the high energy cost in dehydration processes. This work represents an innovative and sustainable solution for overcoming the disadvantages associated with the high costs of stabilization, turning this by-products into high value-added ingredients, from both, nutritional and technological, points of view. The main aim was to develop a microwave coupled with hot air drying technique (HAD + MW) allowing maximizing profits by using the following strategy: reducing time and operational costs, producing a new ingredient rich in dietary fiber, with interesting technological properties for the development of healthy foods, studying the proposed comprehensive process and analyzing the new generated by-products.

The specific objectives were (i) to develop a thermodynamic model for understanding internal heating and water transport mechanisms occurring from the inside to the outside of orange peels during $\mathrm{HAD}+\mathrm{MW}$ drying and to predict the chemical and structural transformations, (ii) to determine the sorption isotherms and the isosteric heat of sorption and to study its effect on the macrostructure and microstructure of the orange peel, (iii) to develop and to determine dielectric tools to predict the moisture and water activity by using dielectric spectroscopy and sorption isotherms, (iv) to compare the energy consumption of hot air drying (HAD) versus HAD + MW by analysing the physico-chemical and technological properties of the dietary fibre obtained and (v) to asses the technological and sensory properties of the new fiber obtained by using it as a fat replacer in potato pures. 


\section{Materials and Methods}

Oranges (Citrus sinensis (L.) Osbeck var Washington Navel) were bought from a local supermarket in Valencia (Spain), and their peel was used for the experiments. Sixty orange peel cylinders (20 mm diameter and $3 \mathrm{~mm}$ thickness) were obtained using a core borer.

The size and shape of the samples were designed to resemble the small pieces of orange peel left after mechanical extraction of juice and the cuts made by a hammer crusher machine in the processing of orange peel. A diagram of the experimental procedure is shown in Fig. 1.

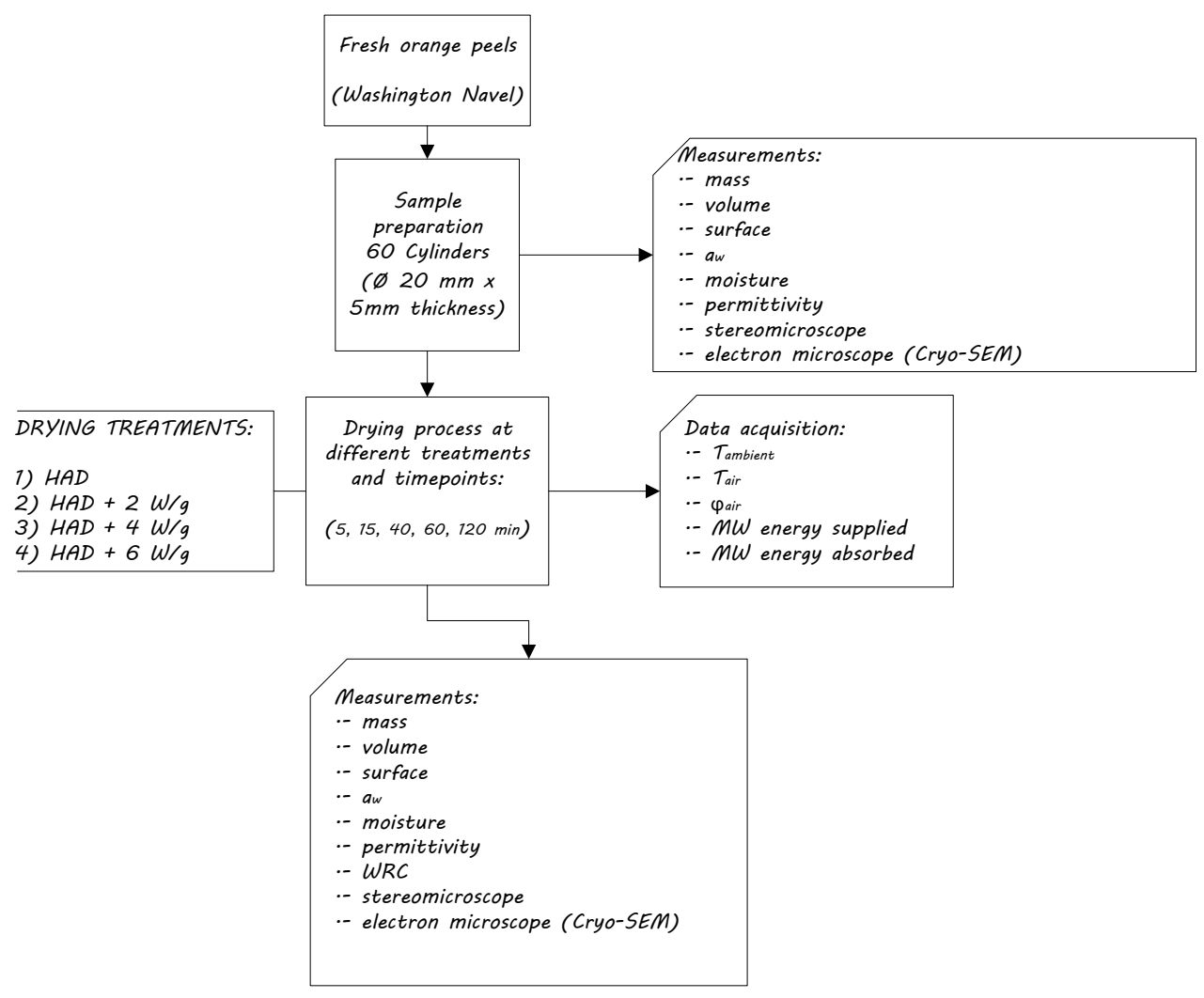

Fig. 1: Experimental procedure

Samples were subjected to HAD + MW, using a specially designed MW-air drying oven with a maximum output of $2000 \mathrm{~W}$ at $2450 \mathrm{MHz}$. For the experiments, the air velocity was $2.5 \mathrm{~m} / \mathrm{s}$, hot air temperature, $55^{\circ} \mathrm{C}$, and the MW energy, 0, 2, 4 or $6 \mathrm{~W} / \mathrm{g}$. Four drying experiments were carried out (HAD, HAD $+2 \mathrm{~W} / \mathrm{g}, \mathrm{HAD}+4 \mathrm{~W} / \mathrm{g}$ and $\mathrm{HAD}+6 \mathrm{~W} / \mathrm{g})$. Three orange peels samples (triplicate) were used for each drying time (5, 15, 40, 60 and 
New technique of combined hot air and microwave drying to produce a new fiber ingredient from industrial byproducts

$120 \mathrm{~min})$ in each drying experiment. For fiber production, samples were milled after drying, using an ultracentrifuge mill (ZM 100, Retsch, Haan, Germany) with a sieve of 500 $\mu \mathrm{m}$. At this stage, powder samples were sealed in plastic bags for further characterization.

\subsection{Mass, volume, surface, $a_{w}$ and moisture content}

Samples were weighed using a precision balance Mettler Toledo AB304-S (precision: \pm $0.001 \mathrm{~g}$ ). Surface water activity was determined employing a dew point hygrometer Decagon Aqualab ${ }^{\circledR}$, series 3 TE (precision: \pm 0.003 , dimensionless) (Decagon Devices Inc., Pullman, WA, USA). Measurements were performed using structured (not minced) samples; thus, the obtained $a_{w}$ was considered the surface $a_{w}$. The water content of representative fresh orange peel sample and the samples dried for 120 min was determined. The samples were dried in a vacuum oven at $60{ }^{\circ} \mathrm{C}$ until constant weight was reached (AOAC method 934.06 2000). The moisture content of the samples at the intermediate stages was calculated from the weight loss during drying. Volume was determined by image analysis (Sony T90, Carl Zeiss optics), using Adobe Photoshop® software, obtaining the diameter and thickness of the samples in triplicate.

\subsection{Microstructure}

The microstructure of fresh and dried samples was analysed using Cryo-SEM. A CryoACryostage CT-1500C unit (Oxford Instruments, Witney, UK), coupled to a Jeol JSM-5410 scanning electron microscope (Jeol, Tokyo, Japan), was employed.

The samples were also examined under a Leica $\mathrm{MZ} \mathrm{APO}^{\mathrm{TM}}$ stereomicroscope (Leica Microsystems, Wetzlar, Germany) with a magnification of $8 \times$ to $80 \times$.

\subsection{Permittivity}

The permittivity was measured with an Agilent 85070E open-ended coaxial probe connected to an Agilent E8362B Vector Network Analyser. The system was calibrated by using three different types of loads: air, short-circuit and $25^{\circ} \mathrm{C}$ Milli ${ }^{\circledR}-\mathrm{Q}$ water. All determinations were made from $500 \mathrm{MHz}$ to $20 \mathrm{GHz}$.

\subsection{Water retention capacity and sweeling capacity}

For the determination of WRC, approximately $0.5 \mathrm{~g}$ of each sample (precision $\pm 0.0001 \mathrm{~g}$ ) was hydrated in $20 \mathrm{~mL}$ of distilled water in a $50 \mathrm{~mL}$ (adapted from Robertson et al. 2000). Swelling capacity, defined as the ratio of the volume occupied when the sample is immersed in excess of water after equilibration to the sample weight, was measured by the method of Raghavendra, Rastogi, Raghavarao and Tharanathan [39]. To 0.2 g of dry sample placed in a graduated test tube; around $10 \mathrm{~mL}$ of water was added to hydrate the sample for $18 \mathrm{~h}$; then the final volume attained by fiber was measured and expressed as volume/g of original sample (dry weight). 


\subsection{Rheology}

The rheological characterization of the samples was carried out using a controlled-stress AR 2000 rheometer (TA Instruments, Leatherhead, United Kingdom). Stainless steel parallel plate geometry of $40 \mathrm{~mm}$ diameter was used with a gap of $2 \mathrm{~mm}$.

\subsection{Sensory analysis}

The sensory analysis of the purées was carried out by a panel formed by 7 trained tasters applying a quantitative descriptive analysis (QDA) according to the UNE-ISO 6658: 2008 and UNE 87025: 1996 standards. Unstructured scales of 10 points were used to analyze 6 sensorial attributes: 2 visually (homogeneity and viscosity) and 4 on the palate (granularity, fat character, creaminess and viscosity). Each taster evaluated 6 samples of potato puree in triplicate: HAD, HAD + $2 \mathrm{~W} / \mathrm{g}$, HAD $+4 \mathrm{~W} / \mathrm{g}$, commercial fiber, no fiber and the reference puree.

\subsection{Statitcal analysis}

To determine the statistical significance of the results, an analysis of variance (ANOVA) was carried out with confidence levels of $95 \%(p \leq 0.05)$ and $99 \%(p \leq 0.01)$ using the Statgraphics Plus 5.1 programme.

For the sensory analysis the statistical analysis was carried out through the R-project program (R version 3.0.1.) applying a one-way ANOVA to determine the significance of the differences between samples for the parameters analyzed. In addition, a contrast test (Tukey test) has been applied to establish among which samples these differences exist.

\section{Results and discussion}

A thermodynamic model was developed to explain the mechanisms involved in mass and energy transports throughout the combined drying by hot air and microwave. A continuous shrinkage in HAD samples was produced by the internal liquid water losses, and the samples treated by HAD+MW showed an internal swelling caused by the internal evaporation produced by the microwave energy. Depending on the predominant mechanisms (HAD shrinkage and MW swelling) samples suffer volumetric expansions or contractions (Fig. 2). 
New technique of combined hot air and microwave drying to produce a new fiber ingredient from industrial byproducts

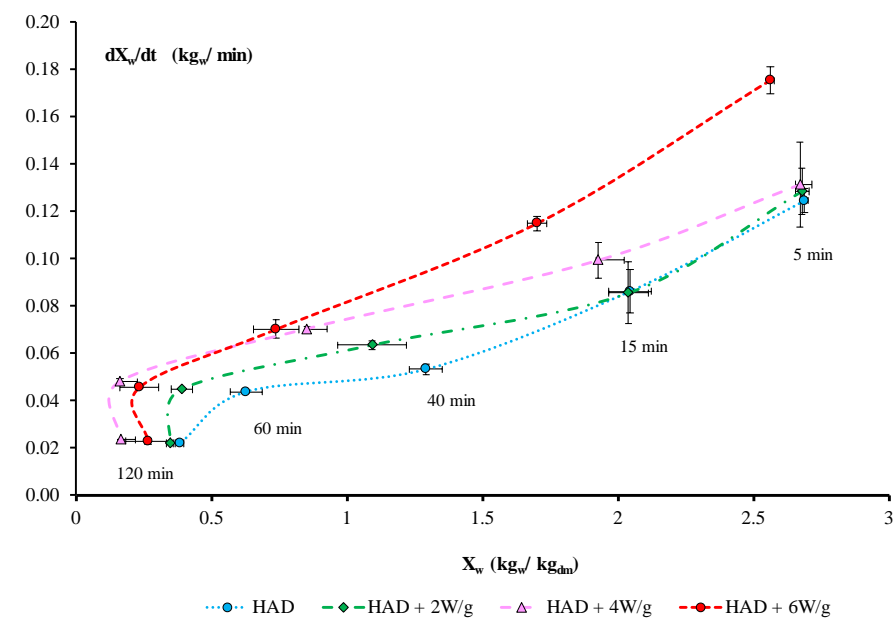

Fig. 2 Drying rate of orange peel samples dried by $H A D$ and $H A D+M W$ at different power intensities. Data represent means and standard deviation of experiments performed in triplicate.

The desorption isotherms of orange peel dried using different treatments (HAD + MW) were obtained and analysed. The results showed that the GAB model could be used to predict the moisture levels using the $\mathrm{a}_{\mathrm{w}}$ measurements. The macrostructural and microstructural transformations were demonstrated and discussed in [1], taking into account the interactions of water with the tissue. The observed shrinkage/swelling phenomena clearly depended on the MW power and on the nature of the tissue.

It was possible to develop a dielectric isotherm technique (Fig. 3) by adapting the GAB model to predict the water activity in dried orange peel by using $\varepsilon^{\prime}(20 \mathrm{GHz})$. The physical meaning of the dielectric isotherm parameters ( $\varepsilon_{0}^{\prime}$ and $\mathrm{Cd}$ ) was studied and explained in [2]. The value of $\varepsilon_{0}^{\prime}$ at $20 \mathrm{GHz}$ ( $\gamma$-dispersion) represents the induction effect of the minimum quantity of adsorbed water or the monomolecular moisture layer. The parameter $\mathrm{Cd}$ is related with isosteric heat or the adsorption energy of the monomolecular moisture layer, as well as the $\mathrm{C}$ parameter of the GAB model. The application of MW power produced an increase of the isosteric heat or adsorption energy of the monomolecular layer, improving the surface tension of samples and thus the hygroscopicity, explaining the reduction of the $\varepsilon_{0}$ ' independently of the quantity of the water molecules adsorbed. 


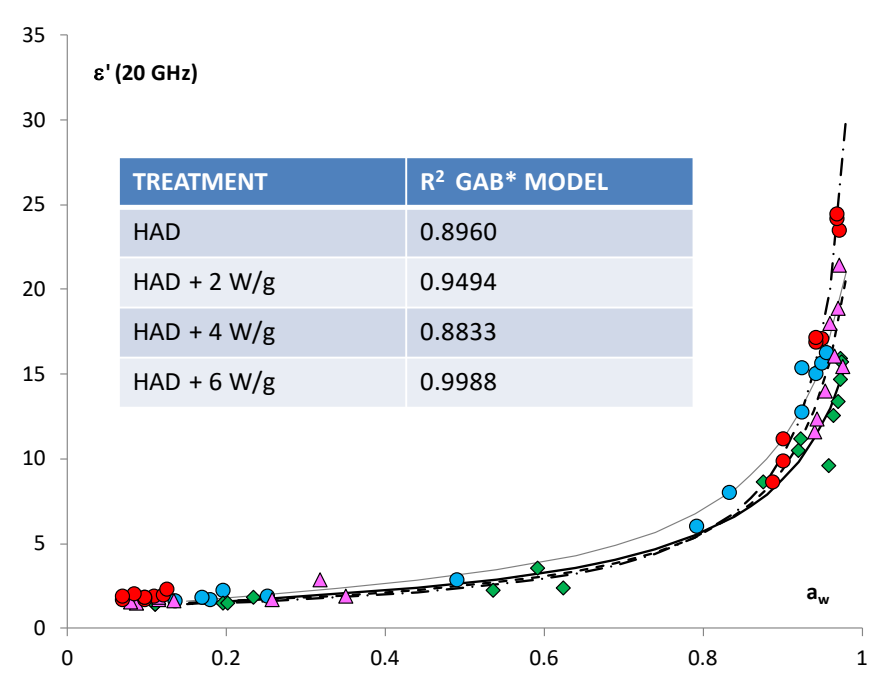

Fig. 3 Dielectric isotherm at $20 \mathrm{GHz}$ of orange peel treated by different drying treatments. Color code same as Fig 2.

An important reduction in processing time (92\%) and energy consumption (77\%) was achieved compared to HAD. The drying treatment did not affect chemical composition or water retention capacities orange fibers. Total dietary fiber content was about $60 \%$ with a ratio of soluble to insoluble fiber of $1: 1$. Although viscosity of both treatments showed similar values [3], the higher swelling capacity of HAD + MW treated fiber provoked a significant decrease in the viscoelasticity of the samples. An increase in particle size due to an increase in porosity during drying [4], improved fiber swelling capacity (Fig. 4).

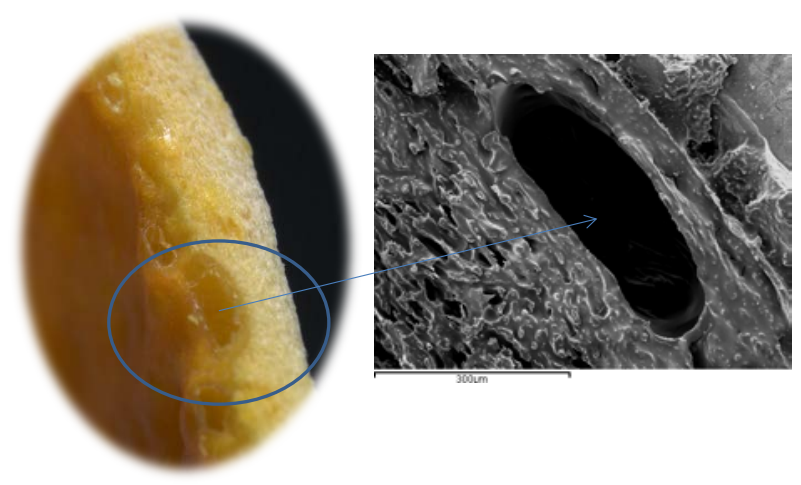

Fig. 4. Micrographs of orange peel samples dried by HAD $+2 \mathrm{~W} / \mathrm{g}$. 
New technique of combined hot air and microwave drying to produce a new fiber ingredient from industrial byproducts

The fat content of processed potato purées with cream was reduced by $50 \%$ using different types of citrus fiber. All the fibers increased the visual viscosity and in mouth of the purées, as well as their behaviour viscoelastic The fibers obtained by air combined drying hotmicrowave (4 W / g) presented a swelling capacity similar to commercial fiber. In addition, these fibers were perceived as more granular in the mouth which can be explained due to the greater volume increase when rehydrating.

\section{Conclusions}

This study has analyzed the microwave coupled with hot air process, developing tools that allow the adequate upscaling of the drying operation by adapting it to the best standards of quality of the final product. A monitoring system that ensures these standards has been designed. This model allows optimizing the traditional hot air drying, by coupling microwave, of orange peel waste as a novel process for citrus by-products valorization, reducing the process time and, therefore, process costs.

The quality and the energy consumption of the dietary fiber production process has been improved. The properties associated with its inclusion in food matrices have been optimized. Therefore, it can be concluded that combining the microwave treatment with hot air drying not only reduced the processing time but it also generated microstructural changes in the dried tissue that increase its water retention capacity. This improved the technological properties of this stabilised by-product, which will be of benefit during its further conversion into the dietary fibre.

\section{References}

[1] Talens, C.; Castro-Giraldez, M.; Fito, P. J., A thermodynamic model for hot air microwave drying of orange peel. Journal of Food Engineering. 2016 (175), 33-42.

[2] Talens, C.; Castro-Giraldez, M.; Fito, P. J., Study of the effect of microwave power coupled with hot air drying on orange peel by dielectric spectroscopy. LWT - Food Science and Technology 2016 (66), 622-628.

[3] Talens, C.; Arboleya, J. C.; Castro-Giraldez, M.; Fito, P. J., Effect of microwave power coupled with hot air drying on process efficiency and physico-chemical properties of a new dietary fibre ingredient obtained from orange peel. LWT - Food Science and Technology 2017 (77), 110-118.

[4] Talens, C.; Castro-Giraldez, M.; Fito, P. J., Effect of Microwave Power Coupled with Hot Air Drying on Sorption Isotherms and Microstructure of Orange Peel. Food and Bioprocess Technology 2018, 11 (4), 723-734. 